\section{Ginastera, Alberto}

Geb. 11. 4. 1916 in Buenos Aires;

gest. 25. 6. 1983 in Genf

Der argentinische Komponist A.G. ist einer der wichtigsten Vermittler zwischen Lateinamerikas musikalischem , Nationalismus und den von Europa initiierten zeitgenössischen Techniken. Von spanisch-italienischen Vorfahren abstammend, aufgewachsen im kosmopolitischen Buenos Aires, ausgebildet am Nationalen Konservatorium von dem d'Indy-Schüler José André, entfaltete G. seine musikalische Sprache zunächst unter dem Einfluß Debussys, Ravels und Stravinskys. Bartók und de Falla waren Vorbilder für den Umgang mit der argentinischen Volksmusik, wobei sich G. insbesondere von der Gauchesco- und Criollo-Tradition anregen ließ.

So sind z.B. G.s toccatenähnliche Schlußsätze auf dem kraftvollen 6/8-Rhythmus des GauchoTanzes "Malambo" aufgebaut, auch verwendet er häufig und in mancherlei Abwandlungen und Funktionen den mit kreolischer Musik assoziierten Akkord der leeren Gitarrensaiten.

Mit den beiden 1937, noch während der Konservatoriumszeit geschriebenen Werken, den Danzas Argentinas für Klavier und dem Ballett $\mathrm{Pa}$ nambi (Buenos Aires 1940), begründete G. seinen Ruf als nationalistischer Komponist. Auch sein zweites Ballett Estancia (Buenos Aires 1952), die Obertura para el ,Fausto Criollo (1943) und andere Werke der vierziger Jahre fußen auf einheimischen Themen, Stoffen oder melodischrhythmischen Modellen, ohne sie direkt zu entwickeln. Das Erste Streichquartett (1948) leitet zur zweiten, sich bis zum Höhepunkt der Pampeana Nr. 3 (1954) erstreckenden Phase über, in welcher der Prozeß der Stilisierung und Sublimierung folkloristischen Materials noch weiter vorangetrieben wird. Gleichzeitig verstärkt sich die Assimilierung moderner Kompositionselemente, wie etwa einer Zwölftonreihe in der Ersten Klaviersonate (1952).

Mit dem Zweiten Streichquartett (1958) beginnt G.s nicht-nationale Periode. Darin verbinden sich rhythmische Vitalität und traditionelle Formen mit freier Reihentechnik im Sinne Bergs, mit Mikrotonalität oder Polytonalität, Polyrhythmik oder Aleatorik und erweiterten instrumentalen oder vokalen Quellen. So erforscht G. etwa in den z.T. recht virtuosen Konzerten für Klavier, Violine und Cello (1961-72) sowie in den Estudios
Sinfónicos (1967) neue Klangmöglichkeiten innerhalb der beibehaltenen Sonaten- oder Variationsform. Sein Interesse am Mythischen zeigt sich in der auf präkolumbische Texte bezogenen Cantata para América Mágica (1960) für Sopran und Schlagzeug, eine Art Beschwörung der altamerikanischen Lebenswelt mit zeitgenössischen Mitteln. G.s Vorliebe für das Phantastische und Surrealistische und seine Hinwendung zum Neo-Expressionismus wird besonders deutlich in den auf historischen Stoffen aufgebauten Opern Don Rodrigo (Buenos Aires 1964), Bomarzo (Washington D. C. 1967) und Beatrix Cenci (Washington D. C. 1971). Daß dabei - trotz neuer Vokaltechniken die Priorität des Melodischen gewahrt bleibt, läßt sich auch an dem Chorwerk Turbae ad Passionem Gregorianam (1974) feststellen. In einigen der späteren Werke, wie z. B. in Popul Vuh (1975) für Orchester oder in der Zweiten Klaviersonate (1981), macht sich G.s Verwurzelung im lateinamerikanischen Kontinent wieder stärker bemerkbar.

Die Krönung in der beruflichen Laufbahn des bereits in jungen Jahren $z u$ internationalen Erfolgen gelangten und durch zahlreiche Preise, Ehrungen und Auftragswerke ausgezeichneten A. G. bestand - nach vorangehenden Lehrtätigkeiten in Buenos Aires und La Plata - in der Leitung des Lateinamerikanischen Zentrums für Höhere Musikalische Studien am Instituto Torcuato Di Tella in Buenos Aires (1962-70), in der sich unter Obhut namhafter Komponisten wie Messiaen, Nono oder Xenakis ein Großteil der heute führenden lateinamerikanischen Komponisten fortgebildet hat.

Noten: Boosey \& Hawkes (Ldn. und N.Y.); Ricordi Americana (Buenos Aires).

Dokumente: Personal viewpoint [zu I. Stravinsky] in Tempo 81 (1967), $20 \mathrm{ff}$. Homage to Béla Bartók in Tempo 136 (1981), $3 \mathrm{ff}$.

Werkverzeichnis: A.G.: A Catalogue of his Published Works, Ldn. und N.Y. 1976. Musikmanuskripte, hrsg. von M. Kuss und L. Handschin, Winterthur 1990 (Inventare der Paul-Sacher-Stiftung 8).

Literatur: Chase, G.: A.G., Argentine Composer in MQ 153 (1957), 439-460. WALLACE, D.E.: A. G. An analysis of his style and techniques of composition, Illinois 1964. HandeY, M.A.: The solo piano compositions of A.G., Cincinatti 1969. StornI, E.: G., Madrid 1983. A. G., hrsg. von Fr. Spangemacher, Bonn 1984 (Musik der Zeit, 4) [mit WV und Bibl]. KING, T.R.: The sacred choral music of A. G. Diss. University of Illinois 1993. Scarabino, G.: A.G. técnicas y estilo (1935-1954), Buenos Aires 1996.

Monika Fürst-Heidtmann 